\title{
Geochemical Characteristics of Crude Oil in Qinggeletu Area, Linhe Depression of Hetao Basin, China: Implication for Oil-Source Correlation
}

\author{
JIANSHE WEI $^{*}$, QIAO ZHANG ${ }^{2}$
}

${ }^{1}$ Xi'an Center of China Geological Survey/ Northest China Center for Geoscience Innovation, Xi'an 710054, Shaanxi, China ("correspondence: upcwjs@126.com)

${ }^{2}$ Xi'an Center of China Geological Survey/ Northest China Center for Geoscience Innovation, Xi'an 710054, Shaanxi, China (hotrock2012zq@163.com)

After over four decades of exploration, the hydrocarbon discovery and exploration targets selection have been made in the Hetao Basin recently. In this paper, the crude oil of 4 wells (including Well Qingqian1 et al.) in Qinggeletu area of Jixi uplift has been analyzed from the aspects of basic physical properties, group components, carbon isotopes, gas chromatgraphy-mass spectrometry (GC-MS), terpane and sterane compounds. The results indicate that the crude oil in the study area is heavy oil, and it is the product of slight secondary degradation when the deep normal crude oil migrated to the shallow parts along the faults. The geochemical characteristics of crude oil in the 4 wells are similar:1 the stable carbon isotope values range from-28\% to-24\%o. (2)the gas chromatograms of saturated hydrocarbons appears as a single-peak type, with the phytane (Ph) dominance. (3)the terpane compounds are characterized by a high content of gammacerane; and 4) the distribution patterns of regular steranes $\left(\mathrm{C}_{27}, \mathrm{C}_{28}\right.$ and $\left.\mathrm{C}_{29}\right)$ appear to be in asymmetrical shaped-"L", with the $\mathrm{C}_{27}$ sterane dominance. As the aforementioned, the results indicate that the paleoenvironments of the source rock was strong reducing and high paleo-salinity conditions in the lacustrine, and the organic matter origins are predominantly aquatic microorganisms, with incorporations of terrestrial higher plants. According to the characteristics of biomarkers and GC-MS of saturated hydrocarbons, the crude oils were formed in the thermal-mature stage. Based on the biomarkers characteristics (terpanes and steranes), the crude oils show favorable correlations with the source rocks in Cretaceous Guyuan Formation, while the crude oil show poor correlations with the source rock in the Paleogene Linhe Formation. 